\title{
Synthesis of novel 6-substituted amino-9-( $\beta$-D-ribofuranosyl)purine analogs and their bioactivities on human epithelial cancer cells
}

\author{
Meral Tuncbilek $^{\mathrm{a}, *}$, Aslıgul Kucukdumlu ${ }^{\mathrm{a}}$, Ebru Bilget Guven ${ }^{\mathrm{b}}$, Duygu Altiparmak ${ }^{\mathrm{a}}$, Rengul Cetin-Atalay ${ }^{\mathrm{c}, *}$ \\ a Department of Pharmaceutical Chemistry, Faculty of Pharmacy, Ankara University, 06100 Ankara, Turkey \\ ${ }^{\mathrm{b}}$ Department of Molecular Biology and Genetics, Bilkent University, 06800 Ankara, Turkey \\ ' Cancer Systems Biology Laboratory, Graduate School of Informatics, ODTU, Ankara 06800, Turkey
}

\section{A R T I C L E I N F O}

Article history:

Received 13 September 2017

Revised 29 December 2017

Accepted 31 December 2017

Available online 2 January 2018

\section{Keywords:}

Nucleoside analogs

Microwave-assisted synthesis

Cytotoxic activity

Hepatocellular carcinoma

\begin{abstract}
A B S T R A C T
New nucleoside derivatives with nitrogen substitution at the C-6 position were prepared and screened initially for their in vitro anticancer bioactivity against human epithelial cancer cells (liver Huh7, colon HCT116, breast MCF7) by the NCI-sulforhodamine B assay. $\mathrm{N}^{6}$-(4-trifluoromethylphenyl)piperazine ana$\log (\mathbf{2 7})$ exhibited promising cytotoxic activity. The compound 27 was more cytotoxic $\left(\mathrm{IC}_{50}=1-4 \mu \mathrm{M}\right)$ than 5-FU, fludarabine on Huh7, HCT116 and MCF7 cell lines. The most potent nucleosides $(\mathbf{1 1}, \mathbf{1 3}, \mathbf{1 6}$, $18,19,21,27,28$ ) were further screened for their cytotoxicity in hepatocellular cancer cell lines. The compound 27 demonstrated the highest cytotoxic activity against Huh7, Mahlavu and FOCUS cells $\left(\mathrm{IC}_{50}=1,3\right.$ and $1 \mu \mathrm{M}$ respectively). Physicochemical properties, drug-likeness, and drug score profiles of the molecules showed that they are estimated to be orally bioavailable. The results pointed that the novel derivatives would be potential drug candidates.
\end{abstract}

(c) 2018 Elsevier Ltd. All rights reserved.
Cancer is one of the most important causes of death in the world, with almost 14 million new patients and 8.2 million deaths from cancer in $2012 .{ }^{1}$ Therefore, development of new potent and selective anticancer agents is of high interest to medicinal chemistry. Nucleobase and nucleoside analogs are often exploited as chemotherapeutic agents in both hematologic malignancies and solid cancers. Nucleobases and nucleosides are the nucleotide precursors; therefore, they are considered as antimetabolites. Nucleotide compounds of similar structure, are involved in many cell processes such as cell growth and division, hence nucleobase and nucleosides have often been exploited as antineoplastic agents. ${ }^{2,3}$ The mechanism of action of nucleobase analogs is through induction of apoptosis. ${ }^{4}$-Fluorouracil which is a nucleobase derivative with fluorine atom, is a frequently preferred anticancer agent for a variety of malignancies in clinics..$^{5}$ Similarly, other pyrimidine nucleosides like cytarabine and gemcitabine have been described as antimetabolite anticancer drugs. ${ }^{6}$ For the last six decades, 6mercaptopurine and 6-thioguanine have been used as a nucleic acid metabolism inhibitor for the treatment of paediatric acute lymphoblastic leukaemia. ${ }^{7}$ Furthermore, purine nucleosides such as fludarabine, cladribine, and pentostatine, have become estab-

\footnotetext{
* Corresponding authors.

E-mail addresses: tuncbile@pharmacy.ankara.edu.tr (M. Tuncbilek), rengul@ metu.edu.tr (R. Cetin-Atalay).
}

lished to be effective against haematological malignancies. ${ }^{8}$ These analogs achieve an unbalance in dNTP pool via inhibition of the ribonucleotide reductase enzyme that induces degradation in DNA synthesis. ${ }^{9}$ Therefore, nucleosides with anticancer bioactivities induce apoptotic cell death in general. ${ }^{6}$

Primary liver cancer, hepatocellular carcinoma (HCC) is second deadly cancer worldwide (GLOBOCAN 2012). It is the fifth most common cancer in men and seventh in women, accounting for $7 \%$ of all cancer cases, worldwide with around 700,000 new cases each year. ${ }^{10-12}$ Ethological factors for primary liver cancer are mainly HBV or HCV infection, chronic alcohol consumption, obesity and environmental toxins (aflatoxin B). ${ }^{10,13}$ Prognosis of HCC patients is usually very poor due to the resistance against conventional chemotherapeutic agents. Sorafenib and regorafenib are FDA approved multikinase inhibitors, which extent patient survival only 3 months with liver cancer. ${ }^{14-17}$ Therefore, it is essential to identify new candidate therapeutic agents for hepatocellular carcinoma. $^{18,19}$

We have previously exploited purine and purine nucleoside derivatives, which have displayed promising cytotoxic activities in liver cancer cells. The molecules from those studies had significant bioactivities on liver cancer cells. The compound $\mathrm{N}^{6}$-(4-trifluoromethylphenyl)piperazine nucleoside $\left(\mathrm{IC}_{50}=5.2-9.2 \mu \mathrm{M}\right)$ induced senescence and purine analogs $\left(\mathrm{IC}_{50}=0.1-0.8 \mu \mathrm{M}\right)$ lead to apoptotic cell death in HCC cell lines. ${ }^{20,21}$ Therefore, we designed 
novel compounds with amine and chlorine electronegative substituents at the $\mathrm{C}-2$ position of the purine ring. These molecules were then synthesized as a new series of 6-substituted amino-9( $\beta$-D-ribofuranosyl)purine derivatives $(\mathbf{9}-\mathbf{2 2}, \mathbf{2 7}, \mathbf{2 8})$ and their cytotoxic activities were screened in human epithelial cancer cells (liver Huh7, colon HCT116, breast MCF7). The bioactivities of the most potent nucleoside derivatives $(\mathbf{1 1}, 13,16,18,19,21,27,28)$ were further analyzed in hepatocellular cancer cell lines (see Figure 1).

The piperazine-containing nucleoside analogs (9-16) were synthesized as shown in Scheme 1. In the first transformation, inosine and guanosine are converted to the 6 -chloro nucleoside $(\mathbf{5 ,}, \mathbf{6})$ with the trifluoroacetic acid anhydride, thionyl chloride method developed by Robins for 2'-deoxyinosine. ${ }^{22}$ Trifluoroacetyl groups were used for transient hydroxyl protection instead of stability of the glycosidic bond. These groups were readily removed by methanolysis after the chlorination reaction. The inosine and guanosine derivatives (9-16) were prepared via nucleophilic aromatic substitution of compounds 7, 8 with 4-substituted piperazines.

Nucleosides substituted with 4-substituted anilines/2-substituted ethyl amines at the position C-6 (17-22), were obtained with nucleophilic aromatic substitution reaction of 6 -chloro-9-( $\beta$-Dribofuranosyl)purine (7) with the suitable anilines and amines under basic conditions (Scheme 1$)$.

The 2-chloro-6-(4-substituted piperazine)/6-(2-substituted ethyl amino) purine analogs $(\mathbf{2 7}, \mathbf{2 8})$ were prepared as shown in Scheme 1. 2,6-Dichloropurine (23) was condensed with the acetylated ribofuranose under microwave irradiation for $30 \mathrm{~min}$ to get 2,6-dichloro-nucleoside derivative (24) in good yield of $79 \%$. The yield obtained as a result of this reaction was significantly higher than the yield in the previously reported method. ${ }^{23,24}$ Displacement of the 6-chloro group was made by nucleophilic aromatic substitution by the substituted piperazine or ethyl amine. Removal of the acetyl groups as the protecting group was made by NaOMe to obtain purine nucleoside analogs $\mathbf{2 7}, \mathbf{2 8}$. The structures of the all compounds were confirmed by ${ }^{1} \mathrm{H},{ }^{13} \mathrm{C}$ NMR mass spectral data and elemental analysis.

The in vitro cytotoxicity of the compounds 9-22, 27, 28 were initially analyzed on Huh7 (liver), HCT116 (colon) and MCF7 (breast) cancer cells, using a sulforhodamine B (SRB) assay. ${ }^{25}$ The $\mathrm{IC}_{50}$ values for each compound also were calculated in comparison with the known nucleobase analog 5-fluorouracil (5-FU), nucleoside analogs fludarabine and cladribine and the results were shown in Table 1. Among the synthesized compounds, analogs accommodating substituted piperazine moiety at their C-6 position $(\mathbf{9}-16,27)$, the one with promising $\mathrm{IC}_{50}$ values against Huh7 $(2 \mu \mathrm{M})$, HCT116 $(1 \mu \mathrm{M})$ and MCF7 $(4 \mu \mathrm{M})$ is trifluoromethylphenyl substituted piperazine analogs (27). Nucleoside 27 displayed significant cytotoxic activity for all the cell lines screened. When, $\mathrm{IC}_{50}$ values compared with 5-FU, fludarabine, the compound $\mathbf{2 7}$ had displayed lower values, which are in micromolar concentrations. Compound 27 established a better cytotoxic activity on Huh7 cell ( 2 vs. 30 and 30 for 5-FU, fludarabine respectively), HCT116 (1 vs. 4 and 8 for 5-FU and fludarabine) and MCF7 cells ( 4 vs. 3 and 15 for 5-FU and fludarabine). Also compound 16, bearing a diphenylmethyl substituent at piperazine moiety of the nucleoside, had higher cytotoxic activities when compared to 5FU and known nucleoside drug fludarabine, on Huh7 cells. The substitution of (2-cyclohexenylethyl)amino at C-6 position improved the cytotoxic activity of compound $\mathbf{2 8}$ and the $\mathrm{IC}_{50}$ values for 72 $\mathrm{h}$ of treatment were comparable to those of 5-FU and fludarabine on Huh7 cell line.

We then analyzed the cytotoxic activities of the most potent nucleoside derivatives $(\mathbf{1 1}, \mathbf{1 3}, \mathbf{1 6}, \mathbf{1 8}, \mathbf{1 9}, \mathbf{2 1}, \mathbf{2 7}, \mathbf{2 8})$ in a panel of HCC cells: Huh7, HepG2, Mahlavu, and FOCUS (Table 2). $\mathrm{N}^{6}$-Trifluoromethyl nucleoside analog 27 demonstrated the best cytotoxic activity, with $\mathrm{IC}_{50}$ values of $1-3 \mu \mathrm{M}$ against Huh7, Mahlavu and FOCUS cells (Table 2). The 2-Cyclohexenylethyl amino derivative 21 was also found to be significantly bioactive $\left(\mathrm{IC}_{50} 1 \mu \mathrm{M}\right)$ on HepG2 cell line. Compounds $\mathbf{2 7}$ and $\mathbf{2 1}$ had a better cytotoxic activity than the known cytotoxic drugs 5-FU and fludarabine on HepG2 cells. When there was a bigger diphenylmethyl group at the piperazine (16), we observed that compound $\mathbf{1 6}$ had displayed lower values in micromolar concentrations. Furthermore, nucleoside 13, which had no substitution at the phenyl ring, were cytotoxic to FOCUS cell line with an $\mathrm{IC}_{50}$ values of $9 \mu \mathrm{M}$.

Nucleoside 21 being one of the most active compound, was showed noteworthy $\mathrm{IC}_{50}$ values $\left(\mathrm{IC}_{50}=6 \mu \mathrm{M}\right)$ on HCT116 which were comparable to that of 5-FU $\left(\mathrm{IC}_{50}=4 \mu \mathrm{M}\right)$ and to that of nucleoside analog fludarabine $\left(\mathrm{IC}_{50}=8 \mu \mathrm{M}\right)$ (Table 1$)$. Similarly, the cytotoxic activity on MCF7 cancer cells was significantly low with nucleoside $21\left(\mathrm{IC}_{50}=3 \mu \mathrm{M}\right)$, which was five times more than the known cytotoxic drug fludarabine.

In silico ADME parameters of the new nucleoside analogs 9-22, 27-28, were used to calculate Lipinski's rules, solubility, percentage of absorption (\%ABS) and topological polar surface area (TPSA) (Table 3) (see Supplementary documentation). All compounds have molecular weights smaller than 500 (377.44> MW < 447.47), with the exception of the compounds 16 and 27. The \% $A B S$ values were between the range of $49.72 \%$ and $68.73 \%$, predicting that the synthesized nucleosides might penetrate through cell membrane. ${ }^{26}$ Majority of the synthesized compounds possess the values of TPSA theoretically compatible with acceptable passive oral absorption. The results pointed that the novel derivatives would be potential drug candidates. To further support our in silico predictions, we calculated drug-likeness and drug-scores of these<smiles>Nc1nc(F)nc2c1ncn2C1OC(CO)[C@@H](O)[C@@H]1O</smiles>

Fludarabine<smiles>Nc1nc(Cl)nc2c1ncn2[C@@H]1C[C@H](O)[C@@H](CO)O1</smiles>

Cladribine<smiles></smiles>

Pentostatin

Fig. 1. Structures of fludarabine, cladribine and pentostatine. 

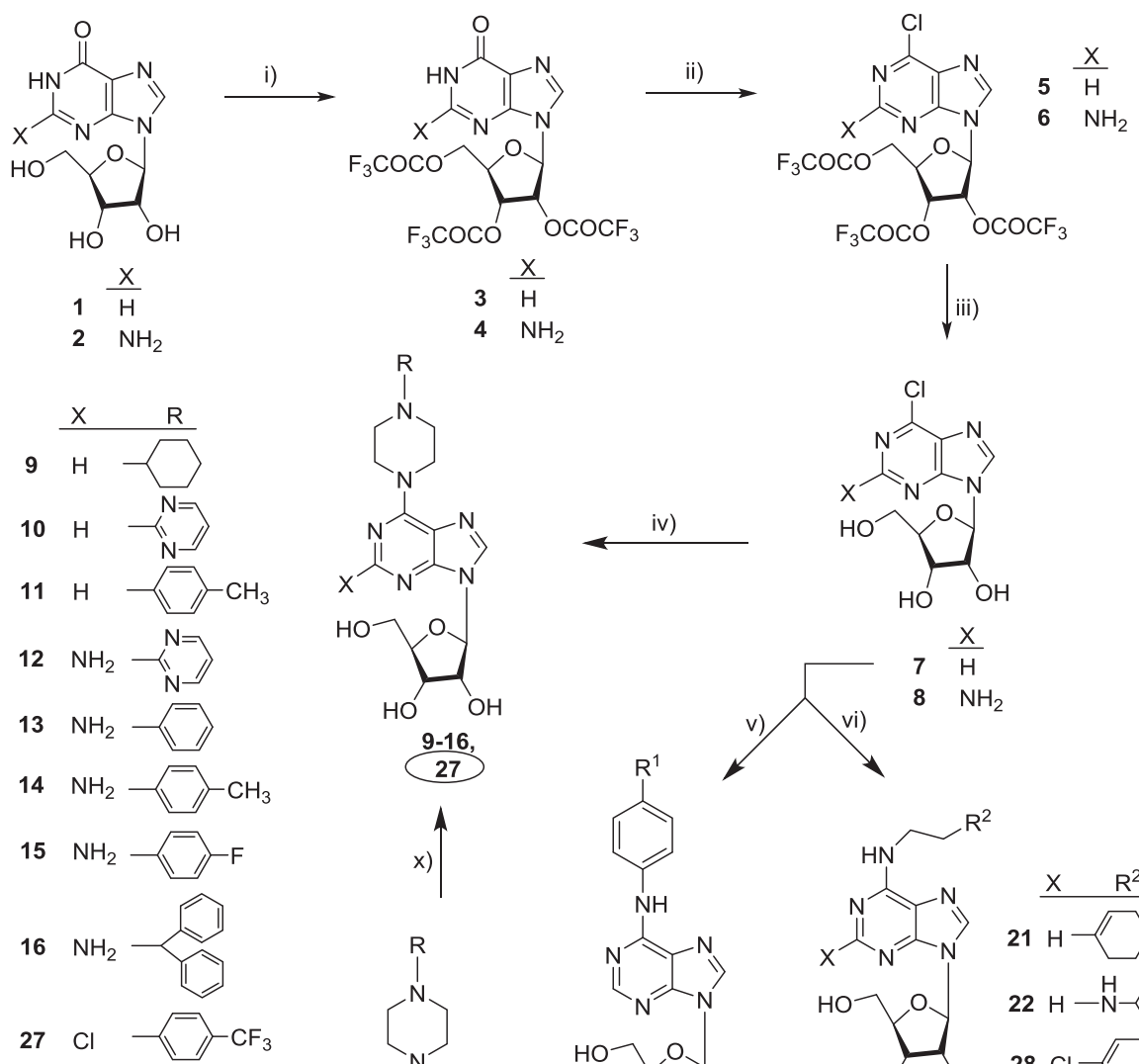<smiles>[2H]N1CCNCC1</smiles><smiles>[Y]c1nc(C)c2ncn(CC3COC(O)C3CO)c2n1</smiles><smiles>[R]N1CCNCC1</smiles>

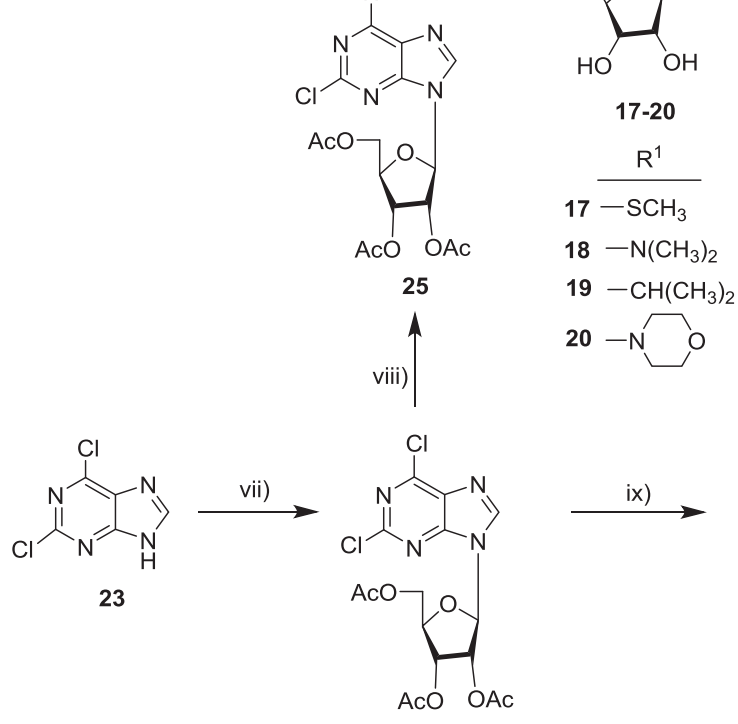<smiles></smiles><smiles></smiles>
iv)

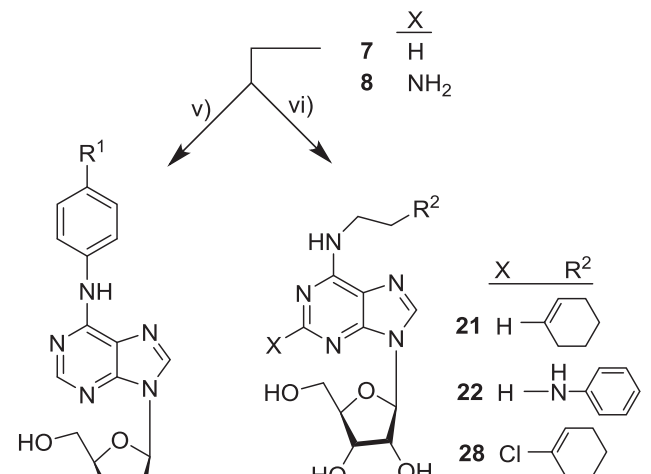

24

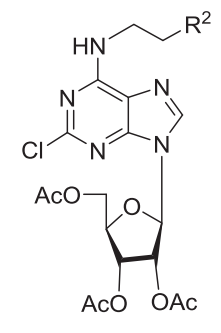

26

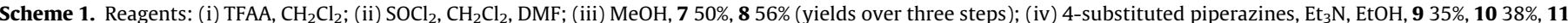

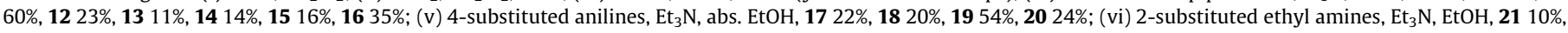

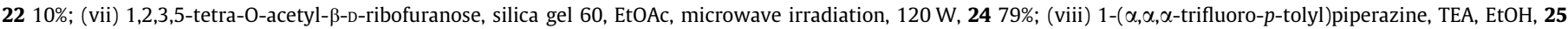
75\%; (ix) 2-(1-cyclohexenyl) ethylamine, TEA, EtOH, 26 62\%; (x) NaOMe, MeOH, 27 87\%, 28 40\%.

compounds which were comparable to those of 5-FU, cladribine and fludarabine $(0.06,0.45$ and 0.46 respectively) in general.

To conclude, fourteen novel nucleoside derivatives $(\mathbf{9 - 2 2})$ bearing substituted piperazine/phenyl amino)/ethyl amino at the C-6 position were designed, synthesized and their bioactivities were assessed in human liver breast and colon epithelial cancer and a set of liver cancer cells. These compounds were acquired with a multistep reactions starting from inosine/guanosine. Alternatively, the condensation of 2,6-dichloropurine with the sugar acetylated $\beta$-D-ribofuranose were efficiently used for the synthesis of 2-chloro nucleoside analogs $(\mathbf{2 7}, \mathbf{2 8})$ and their cytotoxicity were also analyzed on the same set of cancer cells. Our results indicated that the compounds 21, 27 were promising candidates as chemotherapeutic drugs with the $\mathrm{IC}_{50}$ values less than $10 \mu \mathrm{M}$ in Huh7 liver, MCF7 breast and HCT116 colon cancer cells. With the aim of investigating their potential anticancer use in hepatocellular carcinoma 
Table 1

In vitro cytotoxicity of the compounds $\mathbf{9 - 2 2}, \mathbf{2 7}, \mathbf{2 8}$ on different human cancer cell lines (Huh7, HCT116, MCF7)<smiles></smiles>

\begin{tabular}{llll}
\hline \multirow{2}{*}{ Compound } & \multicolumn{2}{l}{ Cancer cell lines, $\mathrm{IC}_{50}(\mu \mathrm{M})^{\mathrm{a}}$} \\
\cline { 2 - 4 } & Huh7 & HCT116 & MCF7 \\
\hline $\mathbf{9}$ & $\mathrm{NI}$ & $>100$ & $\mathrm{NI}$ \\
$\mathbf{1 0}$ & $\mathrm{NI}$ & $>100$ & $40 \pm 2$ \\
$\mathbf{1 1}$ & $\mathrm{NI}$ & $70 \pm 10$ & $>100$ \\
$\mathbf{1 2}$ & $\mathrm{NI}$ & $\mathrm{NI}$ & $\mathrm{NI}$ \\
$\mathbf{1 3}$ & $50 \pm 20$ & $30 \pm 0.2$ & $\mathrm{NI}$ \\
$\mathbf{1 4}$ & $\mathrm{NI}$ & $\mathrm{NI}$ & $\mathrm{NI}$ \\
$\mathbf{1 5}$ & $>100$ & $30 \pm 3$ & $\mathrm{NI}$ \\
$\mathbf{1 6}$ & $10 \pm 1$ & $20 \pm 0.5$ & $20 \pm 0.9$ \\
$\mathbf{1 7}$ & $\mathrm{NI}$ & $>100$ & $\mathrm{NI}$ \\
$\mathbf{1 8}$ & $80 \pm 80$ & $40 \pm 10$ & $30 \pm 8$ \\
$\mathbf{1 9}$ & $60 \pm 40$ & $10 \pm 2$ & $50 \pm 20$ \\
$\mathbf{2 0}$ & $\mathrm{NI}$ & $\mathrm{NI}$ & $80 \pm 60$ \\
$\mathbf{2 1}$ & $>100$ & $6 \pm 1$ & $3 \pm 1$ \\
$\mathbf{2 2}$ & $\mathrm{NI}$ & $30 \pm 10$ & $>100$ \\
$\mathbf{2 7}$ & $2 \pm 0.5$ & $1 \pm 0.2$ & $4 \pm 0.1$ \\
$\mathbf{2 8}$ & $20 \pm 2$ & $90 \pm 100$ & $30 \pm 8$ \\
$\mathbf{5}$-FU & $30 \pm 2$ & $4 \pm 0.3$ & $3 \pm 0.7$ \\
Fludarabine & $30 \pm 20$ & $8 \pm 3$ & $15 \pm 0.1$ \\
Cladribine & $0.9 \pm 0.7$ & $<0.1$ & $2 \pm 2$ \\
\hline
\end{tabular}

a IC50 values were calculated from the cell growth inhibition curves obtained from the treatments done with increasing concentrations of each molecule $(40,20$, 10,5 , and $2.5 \mu \mathrm{M}$ ) for $72 \mathrm{~h}$. Experiments are done in duplicate. NI: No inhibition.
Table 2

IC 50 values of $11,13,16,18,19,21,27,28$ against hepatocellular carcinoma (HCC) cell lines: Huh7, HepG2, MAHLAVU, FOCUS.

\begin{tabular}{lllll}
\hline \multirow{2}{*}{ Compound } & \multicolumn{4}{l}{ HCC cell line, $\mathrm{IC}_{50}(\mu \mathrm{M})^{\mathrm{a}}$} \\
\cline { 2 - 5 } & Huh7 & HepG2 & MAHLAVU & FOCUS \\
\hline $\mathbf{1 1}$ & $\mathrm{NI}$ & $\mathrm{NI}$ & $>100$ & $40 \pm 9$ \\
$\mathbf{1 3}$ & $50 \pm 20$ & $>100$ & $\mathrm{NI}$ & $9 \pm 0.5$ \\
$\mathbf{1 6}$ & $10 \pm 1$ & $20 \pm 4$ & $7 \pm 1$ & $20 \pm 3$ \\
$\mathbf{1 8}$ & $80 \pm 80$ & $30 \pm 10$ & $30 \pm 2$ & $20 \pm 6$ \\
$\mathbf{1 9}$ & $60 \pm 40$ & $40 \pm 8$ & $40 \pm 5$ & $20 \pm 3$ \\
$\mathbf{2 1}$ & $>100$ & $1 \pm 0.2$ & $>100$ & $\mathrm{NI}$ \\
$\mathbf{2 7}$ & $1 \pm 0.06$ & $3 \pm 0.4$ & $3 \pm 0.2$ & $1 \pm 0.01$ \\
$\mathbf{2 8}$ & $20 \pm 2$ & $40 \pm 10$ & $30 \pm 8$ & $50 \pm 20$ \\
$\mathbf{5}$-FU & $30 \pm 2$ & $5 \pm 0.8$ & $10 \pm 2$ & $4 \pm 0.5$ \\
Fludarabine & $30 \pm 20$ & $20 \pm 6$ & $10 \pm 5$ & $10 \pm 1$ \\
Cladribine & $0.4 \pm 0.01$ & $0.04 \pm 0.003$ & $0.1 \pm 0.01$ & $0.4 \pm 0.01$ \\
\hline
\end{tabular}

a IC50 values were calculated from the cell growth inhibition curves obtained from the treatments done with increasing concentrations $(40,20,10,5$, and $2.5 \mu \mathrm{M})$ for the molecules with $\mathrm{IC}_{50}$ values above $2.5 \mu \mathrm{M}$ and $(4,2,1,0.5,0.25,0.125,0.0625$ and $0.03125 \mu \mathrm{M}$ ) for $\mathrm{IC}_{50}$ values below $2.5 \mu \mathrm{M}$ for $72 \mathrm{~h}$. Experiments are done in triplicate. NI: No inhibition.

(HCC), the bioactivities of the compounds $11,13,16,18,19,21,27$, 28 were further tested on a panel of liver cancer cell lines. Compound 21 and 27, which were designed as putative anticancer agents, showed the best biological activities with $\mathrm{IC}_{50}$ values of 1-3 $\mu \mathrm{M}$ on HepG2 liver cancer cells.

\section{Acknowledgements}

This work was supported by the Scientific and Technological Research Council of Turkey-TUBITAK (TBAG-109T987), the KANSIL-2016H121540 (Ministry of Development, Turkey).

\section{A. Supplementary data}

Supplementary data associated with this article can be found, in the online version, at https://doi.org/10.1016/j.bmcl.2017.12.070.

Table 3

Lipinski's rule of 5, \%ABS, TPSA, Log S values, drug likeness and drug scores for the compounds 9-22, 27-28.

\begin{tabular}{|c|c|c|c|c|c|c|c|c|c|c|}
\hline \multirow[t]{2}{*}{ Compound } & \multirow[t]{2}{*}{$\% \mathrm{ABS}$} & \multirow[t]{2}{*}{ TPSA } & \multirow[t]{2}{*}{ Log S at pH 7.4} & \multicolumn{7}{|c|}{ Parameter } \\
\hline & & & & MW & cLog P & nHBA & nHBD & $\mathrm{RB}$ & DL & DS \\
\hline 9 & 68.73 & 116.72 & -1.52 & 420.51 & -1.12 & 10 & 3 & 3 & -5.45 & 0.39 \\
\hline 10 & 58.70 & 145.78 & -2.99 & 414.42 & -0.66 & 11 & 3 & 4 & 0.95 & 0.70 \\
\hline 11 & 67.60 & 120.00 & -4.16 & 426.47 & 1.10 & 9 & 3 & 4 & -1.48 & 0.43 \\
\hline 12 & 49.72 & 171.80 & -3.33 & 429.44 & -0.81 & 12 & 4 & 4 & 3.67 & 0.77 \\
\hline 13 & 59.75 & 142.74 & -2.62 & 429.48 & -1.25 & 11 & 4 & 3 & 4.13 & 0.73 \\
\hline 14 & 58.62 & 146.02 & -4.50 & 441.49 & 0.95 & 10 & 4 & 4 & 1.25 & 0.61 \\
\hline 15 & 59.75 & 142.74 & -2.87 & 447.47 & -1.11 & 11 & 4 & 3 & 1.20 & 0.60 \\
\hline 16 & 59.75 & 142.74 & -2.98 & 519.60 & 0.36 & 11 & 4 & 5 & 4.05 & 0.55 \\
\hline 17 & 66.81 & 122.27 & -3.81 & 391.45 & -0.49 & 9 & 4 & 4 & -2.80 & 0.37 \\
\hline 18 & 65.69 & 125.51 & -2.91 & 388.42 & -1.01 & 10 & 4 & 4 & -9.11 & 0.14 \\
\hline 19 & 66.81 & 122.27 & -4.50 & 387.44 & 0.13 & 9 & 4 & 4 & -5.28 & 0.35 \\
\hline 20 & 62.51 & 134.74 & -3.36 & 430.46 & -1.23 & 11 & 4 & 4 & -4.96 & 0.13 \\
\hline 21 & 66.81 & 122.27 & -3.71 & 377.44 & -0.95 & 9 & 4 & 5 & -8.29 & 0.39 \\
\hline 22 & 62.66 & 134.30 & -3.05 & 388.42 & -1.75 & 10 & 5 & 6 & -5.14 & 0.41 \\
\hline 27 & 68.73 & 116.72 & -4.70 & 516.91 & 0.91 & 10 & 3 & 4 & -6.06 & 0.27 \\
\hline 28 & 66.81 & 122.27 & -4.02 & 411.89 & 0.10 & 9 & 4 & 5 & -5.48 & 0.35 \\
\hline 5-FU & 88.92 & 58.20 & -1.16 & 130.07 & -0.66 & 2 & 2 & 0 & -4.50 & 0.06 \\
\hline Fludarabine & 41.44 & 195.80 & -2.33 & 365.21 & -1.59 & 10 & 5 & 4 & -21.96 & 0.45 \\
\hline Cladribine & 67.84 & 119.30 & -2.90 & 285.69 & -0.28 & 7 & 3 & 2 & 0.89 & 0.46 \\
\hline
\end{tabular}

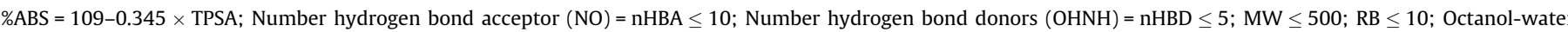
partition coefficient $=\log \mathrm{P}<5$; Solubility $=\log \mathrm{S}$ between -1 and -5 ; TPSA < $140 \AA \AA$; DL: Drug-Likeness score; DS: Drug-Score 


\section{References}

1. Cancer; World Health Organization: http://www.who.int/cancer/en/. Accessed November 4, 2016

2. Bosch L, Harber E, Heidelberger C. Cancer Res. 1958;8:335-343.

3. Shelton J, Lu X, Hollenbaugh JA, Cho JH, Amblard F, Schinazi RF. Chem Rev. 2016;116:14379-14455.

4. Ewald B, Sampath D, Plunkett W. Oncogene. 2008;27:6522-6537.

5. Kuhn JG. Ann Pharmacother. 2001;35:217-227.

6. Sampath D, Rao VA, Plunkett W. Oncogene. 2003;22:9063-9074.

7. Escherich G, Richards S, Stork LJ, Vora AJ. Leukemia. 2011;25:953-959.

8. Lech-Maranda E, Korycka A, Robak T. Mini-Rev Med Chem. 2006;6:575-581.

9. Wilson PK, Mulligan SP, Christopherson RI. Leukemia Res. 2004;28:725-731.

10. Lonardo A, Loria P. J Gastroen Hepatol. 2012;27:1654-1664.

11. Corte CL, Aghemo A, Colombo M. World J Gastroenterol. 2013;19:1359-1371.

12. Subramaniam A, Shanmugam MK, Perumal E, et al. BBA. 2013;1835:46-60.

13. Irmak MB, Ince G, Ozturk M, Cetin Atalay R. Cancer Res. 2003;63:6707-6715.

14. Finn RS. J Hepatol. 2012;56:723-725.
15. Berasain C. Gut. 2013;62:1674-1675.

16. Sugimoto K, Moriyasu F, Saito K, et al. Liver Int. 2013;33:605-615.

17. Gauthier A, Ho M. Hepatol Res. 2013;43:147-154.

18. Ersahin T, Ozturk M, Cetin-Atalay R. Molecular Biology of Liver Cancer. Reviews in Cell Biology and Molecular Medicine, Version of Record online: 27 Jul 2015 DOI: http://doi.org/10.1002/3527600906.mcb.200400024.pub2.

19. Kahraman DC, Hanquet G, Jeanmart L, Lanners S. Med Chem Commun.. 2017;8:81-87.

20. Tuncbilek M, BilgetGuven E, Onder T, Cetin Atalay R. J Med Chem. 2012;55:3058-3065.

21. Demir Z, Bilget Guven E, Ozbey S, Kazak C, Cetin Atalay R, Tuncbilek M. Eur J Med Chem. 2015;89:701-720.

22. Robins MJ, Basom GL. Can J Chem. 1973;51:3161-3169.

23. Andrzejewska M, Kamiński J, Kazimierczuk Z. Nucleos Nucleot Nucl. 2002;21:73-78

24. Korboukh I, Hull-Ryde EA, Rittiner JE, et al. J Med Chem. 2012;55:6467-6477.

25. Shoemaker RH. Nat Rev Cancer. 2006;6:813-823.

26. Lipinski CA. J Pharmacol Toxicol Methods. 2000;44:235-249. 